\title{
LOS PRECEDENTES DEL TRIBUNAL CONSTITUCIONAL EN EL ARBITRAJE
}

\author{
THE TRIBUNAL CONSTITUTIONAL'S \\ PRECEDENTS IN ARBITRATION
}

\author{
Marianella Ledesma Narváez \\ Tribunal Constitucional del Perú, Perú
}

\section{Resumen}

El arbitraje en nuestro país ha sido impactado por las decisiones del Tribunal Constitucional. Estas han tenido gran trascendencia en la actividad arbitral, no solo por el contenido de las interpretaciones, sino porque se les ha dado a esas interpretaciones la connotación o el estatus de precedente. Precisamente, es motivo de este trabajo presentar los dos precedentes que el Tribunal ha fijado en materia arbitral para reflexionar sobre cuán acertadas son las reglas de creación jurisprudencial y cómo impactan estos enunciados sobre la seguridad jurídica.

Palabras clave: arbitraje, precedente, función jurisdiccional, control difuso, negociación colectiva.

\section{Abstract}

The arbitration in our country has been impacted by the decisions of the Constitutional Court. These decisions have had such importance in the arbitration activity, not only because of the content of the interpretations, but because these interpretations have been given the connotation or precedent status. Precisely, it is the reason for this work to present the two precedents that the Court has set in arbitration to reflect on how successful are the 
rules of jurisprudential creation and how these statements impact on legal security.

Keywords: Arbitration, precedent, jurisdictional function, diffuse control, collective bargaining.

\section{Introducción}

El Tribunal Constitucional ha fijado posición sobre la naturaleza jurídica del arbitraje en el proceso de habeas corpus (expediente 06167-2005-PHC/TC-Lima: caso Cantuarias). Ha dicho el Tribunal, en el fundamento 11, lo siguiente:

... la naturaleza propia de la jurisdicción arbitral y las características que la definen, las cuales permiten concluir a este Colegiado que no se trata del ejercicio de un poder sujeto exclusivamente al derecho privado, sino que forma parte esencial del orden público constitucional. La facultad de los árbitros para resolver un conflicto de intereses no se fundamenta en la autonomía de la voluntad de las partes del conflicto, prevista en el artículo 20 inciso 24 literal a de la Constitución, sino que tiene su origen y, en consecuencia, su límite, en el artículo 139.1 de la propia Constitución.

Otro precedente fijado por el Tribunal Constitucional está vinculado con el ejercicio del control difuso por los árbitros, precedente recaído en el caso María Julia (expediente 00142-2011-PA/TC), a fin de inaplicar cualquier norma que se oponga a las reglas, principios y valores de la Constitución. El artículo 138 de la Constitución hace referencia a ese control difuso, pero bajo los supuestos del ejercicio de la función jurisdiccional de los jueces; sin embargo, cuando en la justicia ordinaria un juez decide inaplicar una norma por ser contraria a la Constitución, esa decisión está sujeta al control judicial —de oficio - y a un procedimiento previo para validar o no dicho razonamiento; véase en el caso del artículo 408 del Código Procesal Civil y lo normado en la Ley Orgánica del Poder Judicial, en el que se le ha otorgado dicha competencia de validación a la Sala Constitucional y Social de la Corte Suprema de la República; sin embargo, en el caso del arbitraje, el mero precedente que, interpretando la naturaleza jurisdiccional del arbitraje, le extiende los alcances del artículo 138 de la Constitución (control difuso) no dice nada sobre cómo se ejercerá el control oficioso de ese razonamiento que recurre al control di- 
fuso. Se limita a señalar, en el fundamento 26 del expediente 00142-2011-PA/ TC, lo siguiente:

El control difuso de la jurisdicción arbitral se rige por las disposiciones del artículo VI del Título Preliminar del Código Procesal Constitucional y la jurisprudencia vinculante dictada por este Tribunal Constitucional sobre el control difuso. Solo podrá ejercerse el control difuso de constitucionalidad sobre una norma aplicable al caso de la que dependa la validez del laudo arbitral, siempre que no sea posible obtener de ella una interpretación conforme a la Constitución y además, se verifique la existencia de un perjuicio claro y directo respecto al derecho de alguna de las partes.

Por eso, a través de este trabajo se busca reflexionar sobre los alcances de estos dos precedentes para los efectos de la seguridad jurídica que, desde el arbitraje, se debe preservar en nuestro país.

\section{La naturaleza jurisdiccional del arbitraje}

El contenido de la regla fijada en el fundamento 11 del precedente Cantuarias nos invita a reflexionar: ¿la facultad de los árbitros para resolver un conflicto de intereses no se fundamenta en la autonomía de la voluntad de las partes del conflicto? ¿Es válido asumir que el origen y, en consecuencia, el límite del arbitraje se sostiene en el artículo 139.1 de la propia Constitución?

Estas premisas, así expuestas en el fundamento 11 citado — sobre las que se ha construido la regla que interpreta la naturaleza y alcances del arbitraje-, niegan a la autonomía de voluntad su carácter de piedra angular sobre la que se sostiene el arbitraje y la derivan al contenido del art. 139.1 de la Constitución, la misma que está referida al ejercicio de la función jurisdiccional de los jueces del Poder Judicial.

Hay innegablemente grandes diferencias en relación con el poder delegado de los jueces estatales y los árbitros. Sin ir muy lejos, se debe considerar que la propia Constitución del Estado visibiliza a los árbitros en un estatus diferente del de la actividad judicial. Así tenemos que, mientras la propia Constitución afirma que la función jurisdiccional es incompatible con cualquier otra actividad pública, salvo la docencia (ver artículo 146), esa exigencia de exclusividad no es extensiva al arbitraje, de tal manera que los árbitros pueden ejercer de forma simultánea el arbitraje más su oficio ordinario; a 
lo que se agrega que la función jurisdiccional de los jueces, como parte del poder delegado del Estado, está premunida de algunas exigencias, como la nacionalidad, situación que no se contempla en la actividad arbitral; dicho en otras palabras, para ser juez de la República se requiere ser peruano de nacimiento, situación que no se exige en el arbitraje; por ello, la propia Ley Arbitral (ver D. L. 1071, artículo 20) señala que, salvo acuerdo en contrario de las partes, la nacionalidad de una persona no será obstáculo para que esta actúe como árbitro.

El ejercicio de la función jurisdiccional también está condicionado a contar con una edad límite para desempeñar esa función. En el caso de los jueces de la Corte Suprema, la edad mínima es de 45 años, y, tanto para los jueces del primer eslabón de la carrera judicial como para los jueces de paz letrados, es de 28 años. Este requisito no se exige en la actividad arbitral. Como señala el citado artículo 20 del D. L. 1071, «pueden ser árbitros las personas naturales que se hallen en el pleno ejercicio de sus derechos civiles, siempre que no tengan incompatibilidad para actuar como árbitros».

Como se puede advertir de estas meras referencias, la función jurisdiccional de los jueces estatales no puede estar en la misma dimensión que la de los árbitros ni extenderse a estos, pues el arbitraje tiene su origen y su razón de ser en la autonomía privada de voluntad; sin embargo, este criterio no es aceptado por la regla que ha fijado el Tribunal Constitucional en el fj 11 del caso Cantuarias, ya citado.

No comparto este enunciado, fijado como precedente, y considero que se debe ubicar en su real dimensión al arbitraje, para lo cual se tienen que afirmar dos ideas centrales:

a) El arbitraje se sostiene en el ejercicio de la autonomía privada de voluntades, no en la potestad de la función jurisdiccional del Estado; ambos son escenarios que coexisten y que se interrelacionan en una lógica de complemento para su eficacia, a tal punto que la propia Constitución reconoce a estos dos escenarios para la solución de conflictos derivados de la relación contractual. Véase esta posibilidad en lo dispuesto por el artículo 62 de la Constitución Política: «Los conflictos derivados de la relación contractual solo se solucionan en la vía arbitral o en la judicial, según los mecanismos de protección previstos en el contrato o contemplados en la ley».

b) El arbitraje debe ser apreciado como jurisdicción, concepto que difiere de la función jurisdiccional. Dicho en otras palabras, el término jurisdicción 
no tiene la misma connotación jurídica que la expresión función jurisdiccional. El artículo 139.1 de la Constitución acoge ambos conceptos, pero con una connotación diferente, como lo explicaremos a continuación.

\section{Análisis de la interpretación del precedente}

Para nuestro sistema jurídico nacional la definición de jurisdicción parte de lo establecido en la Constitución Política del Estado, que, en el inciso 1 del artículo 139, consagra la unidad y exclusividad de la función jurisdiccional. No existe ni puede establecerse jurisdicción alguna independiente, con excepción de la militar y la arbitral.

Basta la lectura del citado párrafo para apreciar que las categorías que se acogen en esta fórmula normativa no son las mismas. Una idea es función jurisdiccional y otra es jurisdicción.

Lascano asume que la potestad jurisdiccional no es fraccionable, en el sentido de que conserva toda su fuerza, cualquiera sea el juez que la ejerza ${ }^{1}$; se posee en toda su extensión o no se posee, porque el poder jurisdiccional, como todo poder, es uno e indivisible; solo cuando se tiene todo ese poder es cuando la jurisdicción funciona, y es evidente que el que tiene competencia puede desarrollar la actividad jurisdiccional, que es siempre la misma, cualquiera sea el órgano que la ejerza; por tanto, la potestad jurisdiccional no es fraccionable: se posee o no se posee; así, es una ficción que los árbitros tengan ese poder, pues, tienen una apariencia de este, prueba de ello es que sus mandatos no tienen coerción ni ejecución propia; cuando se requiere de fuerza, tienen que vincularse con la jurisdicción para dar eficacia a sus decisiones. Hay una restricción en ese poder, en ese ejercicio de funciones calificado de jurisdiccional, que no permitiría atribuirse al arbitraje como una expresión de función jurisdiccional. Agrega Lascano razones a su posición: primero, el Estado considera la función jurisdiccional como propia de su soberanía, y siendo así, no puede ser compartida por los particulares; segundo, porque al reducir la materia objeto de la actividad de los árbitros, quita a esta todo carácter jurisdiccional, puesto que es la esencia de la jurisdicción amplia e ilimitada como la soberanía de que emana; tercero, porque no reconoce a los árbitros las facultades o poderes

1 David Lascano, Jurisdicción y competencia (Buenos Aires: Guillermo Kraft, 1941), 216. 
indispensables para el ejercicio de la función jurisdiccional; y cuarto, porque considera al arbitraje como un asunto exclusivamente privado, no admitiendo en ningún momento carácter público al árbitro ni a los actos de este ${ }^{2}$.

Compartimos plenamente la opinión de Lascano, la cual, trasladada a la interpretación del artículo 139.1 de la Constitución, coincide con lo que señala Monroy Gálvez ${ }^{3}$, quien considera que la acepción de jurisdicción, utilizada para nombrar a la actividad en el fuero militar y en el arbitral, no se ajusta al concepto de función jurisdiccional; se trata de un uso incorrecto del concepto. También afirma que la jurisdicción militar y la arbitral son, en estricto, expresiones de una competencia material exclusiva, la primera, y de un procedimiento de heterocomposición, en el caso de la segunda.

Landa ${ }^{4}$, al referirse al arbitraje, lo califica como una jurisdicción de excepción. Señala que, si bien la Constitución consagra los principios de unidad y exclusividad de la función jurisdiccional, que evocan la existencia de un sistema jurisdiccional unitario, de ello no se desprende que el Poder Judicial sea el único encargado de ejercer dicha función, puesto que ello implicaría negar el carácter jurisdiccional del Tribunal Constitucional, del Jurado Nacional de Elecciones, de la jurisdicción especializada del fuero militar y, por extensión, del arbitraje. Frente a esta aseveración, sostenemos que el Poder Judicial no es el único encargado de administrar justicia, pues a ella concurren la actividad de los privados, a través de los medios alternos al sistema judicial, la justicia comunal, e inclusive se incorporan a dicha tarea el Tribunal Constitucional, el Jurado Nacional de Elecciones y la actividad arbitral y militar. Sin embargo, lo que está en discusión es si ellos ejercen una función jurisdiccional en sus intervenciones. No hay que confundir función jurisdiccional con jurisdicción, entendida esta última como sinónimo de competencia en atención a la especialización que el desarrollo de las funciones requiere. El propio mandato constitucional es claro en afirmar la unidad y exclusividad de la función jurisdiccional, pero no de la jurisdicción, pues ella está repartida, como expresión de competencia, entre los diversos ámbitos especializados del

2 Lascano, Jurisdicción y competencia, 153.

3 Juan Monroy, Introducción al proceso civil (Bogotá: Temis, 1996), 230.

4 César Landa, El arbitraje en la Constitución de 1993 y en la jurisprudencia del Tribunal Constitucional (Lima: Themis, Revista de Derecho PUCP), 29-42. 
ejercicio del poder. Como lo señala García Toma ${ }^{5}$, la jurisdicción constitucional supone la imagen de un guardián de la constitucionalidad y está orientada a la racionalización del ejercicio del poder, la supremacía constitucional, la vigencia plena de los derechos fundamentales de la persona y la acción interpretativa e integradora de la Constitución. Considera García Toma que la existencia de la jurisdicción constitucional se justifica en razón de tres consideraciones: a) revisar la inquietante y creciente voracidad legislativa de los órganos estatales; b) la vigorosa defensa de los derechos fundamentales como valladar al abuso y la arbitrariedad estatal; y c) la necesidad de integrar las lagunas constitucionales.

El artículo en comentario tiene su antecedente en la redacción del artículo 233 inciso 1 de la Constitución de 1979; por ello, este resulta una fuente de mirada necesaria para reflexionar sobre lo que se ha calificado como jurisdicción arbitral. Revisando los antecedentes de esta calificación del arbitraje como jurisdicción, nos remitimos al diario de debates de la Constitución de 1979. En él se aprecia que se asumió el arbitraje como jurisdicción por excepción. En una posición contraria, Javier Valle Riestra sostuvo la idea de que no puede afirmarse la existencia de una jurisdicción arbitral; según él, el árbitro tiene la facultad de notio y vocatio, y carece del poder de executio si no recurre al fuero común. En cambio, Roberto Ramírez del Villar sostenía que «en caso no se regulare el arbitraje como jurisdicción estaríamos negando la posibilidad de que los fallos arbitrales tengan fuerza». Esta es la razón de la excepción ${ }^{6}$. García Toma colige que el real motivo de acoger al arbitraje como jurisdicción habría sido el de darle fuerza a los fallos arbitrales; de ahí que la Asamblea Constituyente de 1978 acogió la jurisdicción del arbitraje para que este se vea fortalecido, $y$, de esta manera, se ejerza por los sujetos como una vía alterna donde resuelvan sus controversias ${ }^{7}$.

Estas discrepancias continuaron y se trasladaron a la redacción de la Constitución Política de 1993. En el diario de debates de la Constitución de 1993, el constituyente -Aráoz Esparza ${ }^{8}$ sostenía:

5 Víctor García Toma, Teoría del Estado y derecho constitucional (Lima: Fondo Editorial de la Universidad de Lima, 1999), 324.

6 Comisión Principal de Constitución de la Asamblea Constituyente 1978-1979, Diario de debates, tomo VII, publicación oficial, 217.

7 García, Teoría del Estado, 210.

8 Comisión, Diario, 2302. 
Si bien es cierto que la jurisdicción la ejerce el Estado, y si bien es cierto también que este es un derecho de las personas que tienen diferendos, el de recurrir a esa jurisdicción estatal, que es una garantía de la intervención del Estado para administrar justicia, esas mismas personas podrían voluntariamente acogerse a lo que se llama la jurisdicción voluntaria, que en este caso es la jurisdicción a la que se ha mal llamado jurisdicción arbitral porque en el fondo no es jurisdicción, sino el acto voluntario de las partes que pretenden renunciar a la jurisdicción del Estado para someterse a una jurisdicción particular.

Como se aprecia, el término jurisdicción es utilizado para calificar diversas situaciones, como jurisdicción particular, voluntaria, arbitral y estatal, pues no es un concepto asociado a la función jurisdiccional en su contenido, sino más bien al juez competente para resolver las controversias; pero el tema central no se agota en el escenario a elegir, sino que lo que se buscaba era generar mayor seguridad a los efectos del arbitraje, y para ello se justificó darle un rango constitucional, tal como sucedió con la Constitución de 1979. Ello se puede evidenciar del contenido del debate, como citamos a continuación:

Creo que darle mayor seguridad jurídica, con rango constitucional, a esta jurisdicción arbitral es conveniente. Por un lado, lógicamente va a significar que el Poder Judicial no esté tan abrumado de causas; por otro lado, si quienes tienen un diferendo prefieren que ese sea resuelto por árbitros, no podríamos negarnos a ello. A los que tienen el diferendo y voluntariamente quieren buscar una jurisdicción diferente de la jurisdicción del Estado, que la ejerce el Poder Judicial no tendríamos realmente por qué negarles esa posibilidad. Si bien hay una Ley General Arbitral, si bien es cierto que los arbitrajes están reconocidos en tratados internacionales que suscribió el Perú, creemos que darle rango constitucional a esta norma es preferible a no hacerlo. No significa de modo alguno que desaparezca la jurisdicción arbitral al no estar dentro de la Constitución, pero si quienes utilizan esa jurisdicción desean darle ese rango, no veo por qué tenemos que oponernos a una cosa que es justa y que lógicamente nos haría sintonizar con la voluntad del pueblo peruano.

Otro argumento que se debe considerar es que el Estado ejerce de manera exclusiva la función jurisdiccional como expresión de su soberanía, de tal manera que, cuando los jueces del Estado resuelven los conflictos en la sociedad, lo hacen bajo el compromiso de restablecer la armonía social quebrantada a partir del conflicto; en cambio, en el arbitraje, los árbitros tienen simplemente 
un compromiso: resolver las controversias que las partes han sometido a su competencia, de ahí que se afirme su carácter privado, ya que su origen y reglas dependen de la voluntad de las partes.

Esta situación lleva a que, cuando el Estado delega el ejercicio de dicha función a los jueces, requiere ciertas exigencias en torno al juez que no se dan en el arbitraje, como la nacionalidad, la edad y la dedicación exclusiva a la función jurisdiccional.

Para Lascano 9 , cuando el Estado exige el requisito de la ciudadanía para desempeñar el cargo de juez, es porque ha considerado que la función que este realizará es propia de la soberanía y no puede permitir que sea ejercida por un extranjero. En cambio, como no atribuye ese carácter a la actividad que deben desarrollar los árbitros, no le interesa poco ni mucho la nacionalidad de estos. Aún más, tampoco interesa que los árbitros se dediquen en forma exclusiva a su labor, ni menos los ingresos que puedan percibir por ello. En cambio, el Estado pide a los jueces dedicación exclusiva al ejercicio de la función jurisdiccional y limita las remuneraciones de estos a las que les asigne el presupuesto del Estado y a las que puedan percibir por la investigación y la docencia (véase artículo 146 de la Constitución Política del Estado) y todo ello justificado para garantizar la independencia de los jueces, situación que no sucede con los árbitros, quienes en adición a sus actividades privadas asumen la misión de conocer y definir el conflicto confiado a su oficio. Esto significa que el árbitro no pertenece al aparato burocrático del Estado, en cambio, el juez sí es un funcionario remunerado por el Estado; además, el árbitro no está obligado a aceptar su designación, en cambio, el juez está obligado a conocer la causa que se le confía, salvo que concurran causales que lo lleven a apartarse del caso, por abstención, impedimento o recusación. Las partes pueden elegir a sus árbitros; los jueces, en cambio, son impuestos por Ley; la competencia de los árbitros radica en la autonomía privada de las partes; la competencia de los jueces es por mandato lega ${ }^{10}$.

La materia objeto de la controversia es otro referente para cuestionar la función jurisdiccional del árbitro, pues solo pueden someterse a arbitraje las controversias sobre materias de libre disposición conforme a derecho, así como aquellas que la ley o los tratados o acuerdos internacionales autoricen ${ }^{11}$;

9 Lascano, Jurisdicción y competencia, 132

10 García, Teoría del Estado, 207

11 Decreto Legislativo 1071, artículo 2. 
de lo que se puede advertir que la ley excluye del conocimiento de los árbitros todos los asuntos de orden público o que interesen a la sociedad o que salgan del marco estricto del derecho privado. Vemos que la actividad y capacidad de los árbitros es limitada, en tanto que la de los jueces es amplia, absoluta e ilimitada en principio.

De lo expuesto podemos señalar que no compartimos el precedente fijado en el fj 11 del caso Cantuarias; todo lo contrario, considero que el arbitraje no es ejercicio de función jurisdiccional consagrada en el artículo 139.1 de la Constitución, sino en el ejercicio de la autonomía de voluntad. No se niega que la actividad arbitral pueda vincularse con los atributos de la función jurisdiccional para dotar de eficacia a la actividad arbitral (en la ejecución de laudos por citar), pero esa vinculación posible no la convierte ni transforma su naturaleza de autonomía privada en una de naturaleza jurisdiccional.

Como características básicas del arbitraje se pueden mostrar las siguientes: constituye un derecho - en general- de los particulares someter la decisión de cuestiones controvertidas al arbitraje; opera sobre materias respecto de las cuales las partes pueden libremente disponer; requiere de un convenio arbitral que permita en forma expresa y legítima la intervención del árbitro; y, comprende un procedimiento sencillo y poco formalista que concluye con el laudo arbitral que decide el conflicto y permite la satisfacción forzada de este, si fuere el caso, en sede judicial.

\section{El control difuso en el arbitraje}

Al precedente ya citado, que afirma el carácter jurisdiccional del arbitraje, hay que agregar lo expuesto por el Tribunal Constitucional en el expediente 001422011-PA/TC, referido al caso Minera María Julia. Aquí el TC ha reafirmado la posición ya asumida en el caso Cantuarias (expediente 6167-2005-PHC/TC) en relación con la naturaleza jurisdiccional del arbitraje.

En dicho caso se ha señalado que:

... la naturaleza de jurisdicción independiente del arbitraje, no significa que establezca el ejercicio de sus atribuciones con inobservancia de los principios constitucionales que informan la actividad de todo órgano que administra justicia, tales como el de independencia e imparcialidad de la función jurisdiccional, así como los principios y derechos de la función jurisdiccional. En particular, en tanto ju- 
risdicción, no se encuentra exceptuada de observar directamente todas aquellas garantías que componen el derecho al debido proceso $^{12}$.

La interpretación que asume el Tribunal Constitucional en dicho precedente no supone en lo absoluto desvinculación del esquema constitucional, ni mucho menos del cuadro de derechos y principios reconocidos por la Constitución. Hay una posición dubitativa, pues, sin apartarse del precedente once del caso Cantuarias, reafirma esa posición a la luz de invocar la presencia de la autonomía de voluntades ${ }^{13}$.

Hoy no se puede sostener que el control difuso no es atributo exclusivo de los jueces estatales. Esta actividad también se ha extendido a los árbitros, pues, como señala el artículo 138 de la Constitución, «En todo proceso, de existir incompatibilidad entre una norma constitucional y una norma legal, los jueces prefieren la primera. Igualmente prefieren la norma legal sobre toda otra norma de rango inferior». ¿Esto implicaría que los árbitros pueden ejercer el control difuso al no aplicar una norma cuando es contraria a la Constitución? La respuesta es positiva, y como tal, nos remitimos a las reglas fijadas en el expediente 00142-2011-PA/TC, referido al caso Minera María Julia.

El ejercicio del control difuso por parte de los árbitros lleva a algunas reflexiones. Esta actividad en la justicia estatal requiere, para validarlo de cierto control, la consulta. El juez ordinario que hace uso del control difuso, en un caso en concreto, remite su decisión en consulta, a fin de que sea el superior en grado el que apruebe o no dicha inaplicabilidad. Como señala el inciso 3 del artículo 408 del CPC, la consulta solo procede contra resoluciones de primera instancia en las que el juez haya preferido la norma constitucional a una legal ordinaria. La Corte Suprema, a través de la Sala Constitucional y Social, conoce de las consultas cuando un órgano jurisdiccional resuelve ejerciendo el control difuso ${ }^{14}$.

12 Tribunal Constitucional. Sentencia del 28 de febrero de 2006, en expediente 6167-2005-PHC/ TC, fundamento 9 .

13 En esa misma línea de opinión, encontramos la posición que asume García (Teoría del Estado, 211) cuando sostiene:

... si el Tribunal se acoge a la interpretación literal de la Constitución, entonces no debió indicar a la autonomía privada como el origen del arbitraje, ya que su posición pierde coherencia y consistencia. Ahora, si bien se está convencido que la posición del Tribunal de considerar como jurisdiccional la naturaleza del arbitraje es controvertida, también se cree que este Colegiado debió ser consistente con sus ideas, tanto es así, que si dice por un lado que el origen del arbitraje es jurisdiccional, entonces debió seguir con su orientación; caso contrario sería que el Tribunal cambie su posición y con ello sí hubiera sido valido que manifieste que el origen del arbitraje es la autonomía privada.

14 Véase inciso «c» del artículo 32 de la Ley Orgánica del Poder Judicial. 
Bajo ese razonamiento, ¿los laudos en los que se ejerza dicho control tendrían que ser sometidos necesariamente a consulta ante un órgano jurisdiccional?

En mi opinión, la respuesta es afirmativa, siguiendo el mismo procedimiento y las mismas reglas que siguen los jueces del Poder Judicial cuando hacen control difuso.

Para Hundskopf ${ }^{15}$ :

... en los arbitrajes de Derecho el control difuso es un deber del árbitro. No debemos olvidar que el principio de supremacía constitucional que concurre con el principio de jerarquía normativa es obligatorio para todos, gobernantes y gobernados, sin excepción, por lo tanto no existiría argumento alguno que exima a los árbitros de ejercer un control de constitucionalidad durante el proceso arbitral.

Podría compartir esa tesis, pero la preocupación va más allá de esas posibilidades; se centra en lo que no dice, en cómo se ejercería el control sobre los razonamientos que se trabajen bajo el argumento del control difuso. En igual forma, la regla 26, que fija como precedente el control difuso arbitral, guarda silencio sobre los mecanismos del control; sin embargo, esa misma preocupación ya ha sido materia de reflexión por los jueces de la Sala en lo Comercial de la Corte de Lima, en los seguidos por Provías Nacional con Odebrecht Perú Ingeniería y Construcción S. A. C. sobre anulación de laudo arbitral (Ex-

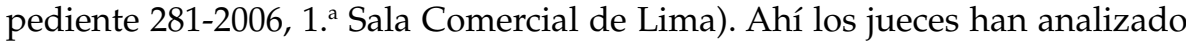
el ejercicio del control difuso por los árbitros y afirmado que, si bien se busca preservar el principio de supremacía constitucional...

... su ejercicio no es un acto simple, requiriéndose, para que él sea válido, la verificación en cada caso de los siguientes presupuestos: a) que en el proceso correspondiente, el objeto de impugnación sea un acto que constituya la aplicación de una norma considerada inconstitucional; b) que la norma a inaplicarse tenga relación directa, principal e indisoluble con la resolución del caso, es decir, que ella sea relevante en la resolución de la controversia; c) que la norma a inaplicarse resulte evidentemente incompatible con la Constitución, aun luego de haberse acudido a interpretarla de conformidad con la Constitución, en virtud del principio enunciado en la $2^{\circ}$ Disposición General de la Ley Orgánica del Tribunal Constitucional.

15 Oswaldo Hundskopf, «Diálogo con la jurisprudencia», en El control difuso en la jurisdicción arbitral (Lima: Gaceta Jurídica, 1991), 17. 
Es importante esta decisión de la Sala Superior que cito, porque expone una preocupación de larga data, aún no trabajada o regulada por el trabajo jurisprudencial; se han establecido las posibilidades del ejercicio, mas no se han diseñado los mecanismos ni el procedimiento a seguir.

Recurrir al control difuso no es un acto ordinario; todo lo contrario: debe contener no solo el análisis de los presupuestos antes mencionados, sino que, además, debe haber, de manera concreta, un escenario de control en el que se compulse si el razonamiento que hace el juez es el correcto para justificar la inaplicación de la norma ordinaria por ser contraria a la Constitución. En el análisis del caso que se tenía que dilucidar ante la Sala Superior, señalaron lo siguiente:

A modo de ejemplo, no se ha precisado en qué radica la incompatibilidad entre el artículo 23 de la Ley 27785 con las facultades contempladas en el segundo párrafo del inciso $2^{\circ}$ del artículo 139 de la Constitución Política, así como tampoco la pertinencia y relevancia de esta última norma al caso concreto, tal como se aprecia en el fundamento 11.18 del laudo.

Se denota asimismo una indebida e incorrecta utilización del control difuso por parte del Tribunal arbitral cuando, no obstante hacer referencia a dicha facultad, luego concluye de manera contradictoria, ante un pedido de aclaración del hoy demandante, que no ha ejercido control difuso, ya que no estaba en un conflicto de leyes... ${ }^{16}$.

A pesar de que el Tribunal Constitucional considera que la autoridad de los árbitros no viene de las partes sino del Estado que los instituye como jueces, aunque sean nombrados por las partes, y, por ello, se comportan como una autoridad jurisdiccional, este criterio - que no comparto- no solo debe leerse afirmando ese extremo de su origen, sino que también debe mirarse en toda su dimensión y extender los procedimientos para controlar el ejercicio del control difuso, tomando como referencia, por remisión, las reglas que guían la función jurisdiccional de los jueces, contenidas en la Ley Orgánica del Poder Judicial y las del Código Procesal Civil. Lo que ha hecho el Tribunal Constitucional es reconocer una facultad-deber del control difuso y guardar silencio sobre el cómo se ejerce este mecanismo a la luz de la normatividad

16 En los seguidos por Provías Nacional con Odebrecht Perú Ingeniería y Construcción S. A. C. sobre anulación de laudo arbitral, expediente 281-2006, 1. ' Sala Comercial de Lima. 
que aplican los jueces estatales - generando con ello un gran vacío-, sin control, a esos razonamientos que, hasta la fecha, los árbitros vienen invocando para inaplicar las normas ordinarias.

No quiero terminar estas líneas sin plantear mi reflexión sobre los efectos que genera para la seguridad jurídica asumir la tesis jurisdiccional del arbitraje en los términos que se exponen en el precedente Cantuarias y que justifica luego la incursión en el control difuso por los árbitros. Lo que tiene que definirse a la luz de dicha corriente asumida por el Tribunal Constitucional son temas derivados de esa posición, como los vinculados con la responsabilidad civil de los árbitros. En la función jurisdiccional, se deriva la indemnización por la mala praxis; véase, por citar, que la propia Constitución reconoce la indemnización por errores judiciales provenientes de procesos penales; en el Código Procesal Civil está regulado el procedimiento para las pretensiones sobre responsabilidad civil de los jueces por ejercicio de función jurisdiccional; si esto es así, me pregunto, ¿estas reglas de responsabilidad civil son extensivas a los árbitros, por asumir también ellos la función jurisdiccional, en los términos del artículo 139.1 de la Constitución? Esta es una pregunta importante a la luz de los últimos acontecimientos que apreciamos en nuestro país, a propósito de la actividad arbitral.

La definición de la naturaleza jurisdiccional del arbitraje no es una mera discusión frívola; todo lo contrario, resulta trascendente para los efectos penales que va a generar asumir la posición de que el arbitraje es función jurisdiccional.

Uno de ellos parte por definir la punición penal de las injurias ante un procedimiento arbitral. En un proceso judicial, se puede «injuriar» y «difamar» al adversario sin que esto implique sanción penal alguna. En efecto, nuestro Código Penal, al igual que otros códigos en Iberoamérica, contempla la atipicidad de la injuria y la difamación «cuando se trata de ofensas proferidas con ánimo de defensa por los litigantes, apoderados o abogados en sus intervenciones orales o escritas ante el juez» (ver artículo 133.1 del Código Penal).

Sin embargo, nos preguntamos si esa atipicidad puede ser extensiva hacia las ofensas que profieran litigantes y abogados en el arbitraje. Aquí hay posiciones divididas. Unos justifican la sanción penal e invocan, para ello, el principio de legalidad y la naturaleza no jurisdiccional del arbitraje, de tal manera que no tiene la misma connotación la ofensa ante el juez que la que se hace ante el árbitro; en cambio, para quienes están en la otra orilla, invocan el pre- 
cedente (STC 6167-2005-HC) sobre la naturaleza «jurisdiccional» del arbitraje, para extender la atipicidad del artículo 133.1 del Código Penal hacia las ofensas que se profieran en el arbitraje. En este escenario de opiniones divididas, no nos queda más que esperar los futuros pronunciamientos judiciales que fijen una posición frente a la posible penalización de las ofensas en el arbitraje.

Otro tema por definir es la responsabilidad penal de quien emite un falso testimonio en el arbitraje. Si bien estamos ante un delito doloso, para que se tipifique la acción u omisión se requiere que el testigo conozca la falsedad de la afirmación, de la negativa o que calle la verdad cuando tiene obligación de declararla. La falsedad debe producirse respecto de hechos con trascendencia probatoria que influyan sobre la decisión a tomarse y que produzcan perjuicio, pues, si recae sobre circunstancias intrascendentes, no habrá delito. Este se halla tipificado como delito contra la administración de justicia y está contenido en el artículo 409 del Código Penal bajo la siguiente redacción legal: «El testigo, perito, traductor o intérprete que en un procedimiento judicial hace falsa declaración sobre los hechos de la causa o emite dictamen, traducción o interpretación falsos será reprimido con pena...». Expuestos así los hechos, nos preguntamos si pueden ser extensivos los efectos del artículo 409 del Código Penal a la declaración de un testigo ante un procedimiento arbitral. En igual forma, esperemos que los futuros pronunciamientos judiciales lo diriman, mientras ponemos a debate esta otra interrogante.

\section{Tribunal Constitucional y control difuso en la negociación colectiva}

Este tema ha sido materia de pronunciamiento del TC en lo que se refiere a los temas laborales (ver expedientes 0003-2013-PI/TC, 0004-2013-PI/TC y 00232013-PI/TC). Ahí se planteó la tesis de que la prohibición de ejercer control difuso en los arbitrajes sobre negociación colectiva de los servidores públicos en materia de incrementos remunerativos es inconstitucional; sin embargo, el pronunciamiento del TC afirmó la constitucionalidad de esta prohibición: en sede arbitral no hay control difuso para incrementos remunerativos.

El Tribunal Constitucional ha sostenido que los arbitrajes en materia laboral se sujetan a las limitaciones señaladas en la misma disposición y en las demás disposiciones legales vigentes. Por lo tanto, se estaría regulando la prohibición de generar gastos corrientes adicionales al presupuesto público. Por ende, y al tratarse de una disposición estrictamente presupuestaria, co- 
rresponde que este tribunal realice el examen de constitucionalidad. Algunos criterios consideran que resulta inconstitucional exigirles a los árbitros que se circunscriban a las disposiciones legales vigentes al emitir sus laudos, y que expresamente se les niegue la facultad de ejercer el control difuso, que es propia de su función jurisdiccional, contraviniendo, de esa manera, lo dispuesto por los artículos 138 y 139.1 de la Constitución.

En contraposición a esta tesis, se argumenta que el control difuso no puede habilitar a los árbitros a actuar de forma contraria al principio de estabilidad presupuestaria, previsto en el artículo 77 de la Constitución. El tribunal consideró que es constitucional esta prohibición. Esto es así porque la disposición bajo examen se limita a reiterar que la realización de los arbitrajes laborales debe adecuarse al ordenamiento legal vigente, reiterando, de esa manera, el principio en virtud del cual todos están obligados a aplicar los mandatos de la ley que se derivan del artículo 103 de la Constitución. Por ende, la prohibición del control difuso en materia de aumento de remuneraciones no lesiona las facultades o competencias de los árbitros en materia laboral.

El caso que hemos citado está referido al control concentrado de normas; sin embargo, he venido advirtiendo que el ejercicio del control difuso en sede arbitral, en los escenarios donde se ha ejercido, no ha tenido mayor control jurisdiccional, pues el precedente recaído en la STC 00142-2011-PA/TC ha guardado silencio sobre el procedimiento y el ámbito donde debería continuar el control oficioso a esa inaplicación de normas, situación que sí sucede en el ámbito de la función jurisdiccional de los jueces del Estado.

\section{Conclusiones}

- La actividad arbitral ha sido impactada por las decisiones del TC. Algunas de las que mayor influencia han tenido son los precedentes vinculantes fijados en el caso Cantuarias (STC 6167-2005-PHC/TC) y en el caso María Julia (STC 00142-2011-PA/TC), en los que se ha establecido y afirmado el carácter jurisdiccional del arbitraje, apartándose de la corriente de la autonomía de voluntad, a partir de la interpretación que se ha hecho del artículo 139 inciso 1 de la Constitución del Estado.

- Afirmar el carácter jurisdiccional ha permitido sostener el control difuso en el arbitraje y ha dejado pendiente en los pronunciamientos judiciales definir los alcances de la responsabilidad civil de los árbitros, la interven- 
ción de los testigos en el arbitraje y los efectos de las ofensas e injurias vertidas en el proceso judicial.

El precedente recaído en el caso María Julia ha reconocido el ejercicio del control difuso en sede arbitral, pero ha guardado silencio sobre los procedimientos y escenarios a los que se debe recurrir para ejercer el control oficioso del razonamiento que inaplica una ley ordinaria por ser contraria a la Constitución. Este vacío, que debió ser completado con la remisión a las reglas del Código Procesal Civil y la propia Ley Orgánica del Poder Judicial, viene afectando la seguridad jurídica en nuestro país, pues se crean y se mantienen escenarios ajenos al control jurisdiccional — de oficio- y con poderes jamás otorgados ni diseñados por el propio legislador, ni menos por el Constituyente. 


\section{REFERENCIAS}

Comisión Principal de Constitución de la Asamblea Constituyente 1978-1979. Diario de los Debates. Tomo VII, publicación oficial.

García Toma, Víctor. Teoría del Estado y derecho constitucional. Lima: Fondo Editorial de la Universidad de Lima, 1999.

Hundskopf, Oswaldo. «Diálogo con la jurisprudencia». En El control difuso en la jurisdicción Arbitral. Lima: Gaceta Jurídica, 1991.

Landa Arroyo, César. «El arbitraje en la Constitución de 1993 y en la jurisprudencia del Tribunal Constitucional». Themis, Revista de Derecho 53 (junio 2007): 29-42. http:/ / revistas.pucp.edu.pe/index.php/themis/article/view/8846.

Lascano, David. Jurisdicción y competencia. Buenos Aires: Guillermo Kraft, 1941.

Monroy, Juan. Introducción al proceso civil. Bogotá: Temis, 1996.

\section{LEYES, SENTENCIAS Y OTROS DOCUMENTOS LEGALES}

Decreto Legislativo 1071.

Tribunal Constitucional. Sentencia del 28 de febrero de 2006, expediente 6167-2005$\mathrm{PHC} / \mathrm{TC}$.

Ley Orgánica del Poder Judicial.

Primera Sala Comercial de Lima, expediente 281-2006. En los seguidos por Provías Nacional con Odebrecht Perú Ingeniería y Construcción S. A. C. sobre anulación de laudo arbitral.

\section{Sobre la autora}

Doctora y bachiller en Derecho por la Universidad Nacional Mayor de San Marcos, magíster universitaria en Justicia Constitucional por la Universidad de Castilla-La Mancha (España), profesora universitaria y autora de diversas publicaciones vinculadas con el derecho procesal y la justicia alterna. Actualmente se desempeña como presidenta del Tribunal Constitucional del Perú. 